\title{
Equipamento Automatizado de Soldagem Capacitiva para Termopares
}

\author{
Igor Rossi Fermo ${ }^{1}$, Rubens Zenko Sakiyama ${ }^{1}$, Marcos de Souza ${ }^{1}$, Cid Marcos Gonçalves Andrade ${ }^{1}$ (D) \\ ${ }^{1}$ Universidade Estadual de Maringá - UEM, Departamento de Engenharia Química, Programa de Pós-graduação em Engenharia Química, Maringá, PR, Brasil.
}

Como citar: Fermo IR, Sakiyama RZ, Souza M, Andrade CMG. Equipamento automatizado de soldagem capacitiva para termopares. Soldagem \& Inspeção. 2019;24:e2417. https://doi.org/10.1590/0104-9224/SI24.17

\begin{abstract}
Resumo: Os termopares são dispositivos elétricos de simples concepção utilizados na medição de temperatura, e possuem um grande uso na indústria. O termopar necessita de uma junção eficiente para os dois fios metálicos que o compõem, que comumente é feita pela soldagem. O processo de soldagem utilizado para construir um termopar pode ser feito de várias maneiras, e a mais comum e eficiente é a soldagem por descarga capacitiva, que irá fundir a liga e criar uma união, mantendo as propriedades dos metais envolvidos e resultar e uma união homogênea dos dois metais. Este trabalho tem como objetivo desenvolver um equipamento capaz de realizar automaticamente esta solda em ambiente inerte, por descarga capacitiva, cujo valor da energia a ser descarregada para a união do termopar é determinada utilizando o princípio da conservação da massa e energia em ligas metálicas e bitolas preestabelecidas de alguns tipos de termopares. Os resultados obtidos com a soldagem de diferentes tipos e bitolas de termopar foram analisados com relação ao aspecto visual e de softwares de análise de imagens, juntamente com curvas de calibração. Os termopares foram considerados de boa qualidade de acordo com os parâmetros de análise estabelecidos, e comparações com termopares comerciais.
\end{abstract}

Palavras-chave: Soldagem de termopares; Solda capacitiva; Equipamento de soldagem.

\section{Automatic Capacitive Welding Equipment for Thermocouples}

Abstract: Thermocouples are electrical devices of simple design used in temperature measurement and have great use in industry. The thermocouple needs an efficient junction for the two metal wires, commonly done by welding. The welding process can be done in several ways, and the most common and efficient is the capacitive discharge welding, that will fuse the alloy and create a joint, maintaining the metal properties and results and a homogeneous joint. This work aims to develop an equipment capable of performing automatically this welding, by capacitive discharge, in inert environment, whose value of energy to be discharged is determined using the principle of conservation of mass and energy in pre-established alloys and gauges of some types of thermocouples. The results obtained with the welding of different types and thermocouple gauges were analyzed according to visual aspect and image analysis software along calibration curves. The thermocouples were considered of good quality according to analysis parameters established, and comparation to commercial thermocouples.

Key-words: Thermocouple welding; Capacitive welding; Welding equipment.

\section{Introdução}

A união de dois metais iguais ou diferentes expostos à temperatura ambiente é realizada por meio do fornecimento de energia para ambas as partes, elevando sua temperatura até o ponto de fusão das ligas metálicas. Um dos métodos mais tradicionais e simples de elevar a temperatura de ligas metálicas é pelo efeito Joule, que consiste em produzir uma intensa corrente elétrica através de um objeto metálico. A colisão de elétrons ocasionado pela corrente elétrica provocará o aquecimento do objeto metálico, sendo o calor gerado proporcional a intensidade da corrente elétrica e ao tempo no qual o metal é submetido a passagem da corrente elétrica.

Técnicas de união de ligas metálicas de pequena espessura são descritas por Tohmyoh et al. [1], o efeito Joule também tem sido utilizado para soldagem de micro e nano fios como relatado por Peng et al. [2]. Técnicas de soldagem mais modernas como feixes laser são relatadas por Kim e Jang [3] e Hu et al. [4], porém estas técnicas envolvem um alto custo e possuem restrição de aplicação dos feixes em determinadas estruturas, ou em pontos de difícil acesso de uma estrutura. Também são relatados por Kumar et al. [5] técnicas de união por vibrações ultrassônicas, que consistem em aplicar pressão juntamente com vibrações da ordem de $22 \mathrm{kHz}$ sobre os objetos metálicos produzindo energia por meio de vibrações na estrutura, fundindo o metal e criando a união, mas ao utilizar-se esta técnica, abre-se mão da simplicidade e baixo custo de produção. 
Devido à necessidade de apenas uma corrente elétrica intensa (kA) em um curto espaço de tempo, o efeito Joule é uma técnica simples e de baixo custo, além disso, essa técnica pode ser aplicada em pontos nos quais outras técnicas de soldagem não podem ser utilizadas.

Segundo Houldcroft [6] o processo de soldagem deve preencher os requisitos de: gerar uma quantidade de energia capaz de unir dois materiais, remover contaminações das superfícies a serem unidas, evitar a contaminação pelo ar atmosférico e propiciar o controle da transformação de fase, alcançando as propriedades desejadas de baixa resistência elétrica e resistência mecânica.

O gás de proteção na soldagem tem a função de proteger a poça de fusão dos efeitos nocivos do oxigênio existente no ar atmosférico Tatagiba et al. [7]. A inclusão de um terceiro elemento no sistema de pares metálicos deve ser evitada para a obtenção de uma maior eficiência e precisão do equipamento de medição de acordo com Thermocouples Operation Principles [8]. O gás de proteção pode ser inerte, não possuindo solubilidade no metal ou pode ser ativo ou até mesmo uma mistura dos dois tipos de gases. São características também atribuídas ao gás de proteção no processo de soldagem a perda de elementos químicos, temperatura da poça de fusão, sensibilidade a fissuração e a porosidade.

Embora estejam disponíveis diferentes tipos de misturas de gases de proteção, desde a binária até a quaternária as mais comuns são à base de $\mathrm{He}, \mathrm{Ar}$ e $\mathrm{CO}_{2}$, sendo a suas proporções no gás de proteção determinadas de acordo com o material a ser soldado e as características do processo.

Uma aplicação comum da soldagem capacitiva em ligas de pequena espessura é na confecção de termopares, o qual é constituído de dois fios de metais puros ou ligas metálicas que precisam ter uma boa condutividade elétrica para assegurar mais precisão em suas medições [9]. A conservação da massa das ligas metálicas envolvidas é importante em uma solda realizada em um termopar, pois não há a inserção de uma terceira liga metálica ou elementos externos no sistema [10].

Termopar ou par termoelétrico são sensores de temperatura de simples concepção, com ampla faixa de medição e precisão, cuja construção se baseia na junção de dois condutores metálicos compostos de metais puros ou ligas metálicas. 0 princípio básico de funcionamento de um termopar está no fato de que dois fios metálicos, diferentes, quando unidos em suas extremidades e estas submetidas a diferentes temperaturas gera uma diferença de potencial. A união de dois segmentos de metais em ambas as extremidades caracteriza o termopar. À extremidade na qual a união é feita atribui-se o nome de junta quente, e essa extremidade é colocada em contato com o corpo cuja temperatura deseja-se medir. A outra extremidade é denominada junta fria. Quando as extremidades são submetidas a uma diferença de temperatura, as diferentes composições ou materiais empregados na solda produzem uma movimentação ordenada de elétrons, obedecendo às leis da termoelétrica descobertas por T. J. Seebeck segundo os princípios de funcionamento do termopar [8]. O termopar possui as características de tamanho reduzido, baixa capacidade térmica e possui um fluxo de energia desprezível de acordo com Thermocouple Theory [11].

Os termopares mais utilizados na indústria são os termopares de base metálica, que são desenvolvidos com ligas metálicas de baixo custo, os quais são divididos em tipos: tipo T (Cobre/Constantan; -180 a $370{ }^{\circ} \mathrm{C}$ ); tipo $\mathrm{E}(\mathrm{Cromel} /$ Constantan; -200 a $900{ }^{\circ} \mathrm{C}$ ); tipo J (Ferro/Constantan; -40 a $750{ }^{\circ} \mathrm{C}$ ); tipo $\mathrm{K}$ (Cromel/Alumel; -180 a $1300{ }^{\circ} \mathrm{C}$ ); tipo $\mathrm{S}$ (Platina/Ródio; -50 a $1768^{\circ} \mathrm{C}$ ); tipo N (Nicrosil/Nisil; -270 a $1300{ }^{\circ} \mathrm{C}$ ) de acordo com Wang [9].

A solda da junta metálica dos termopares é um item importante na qualidade destes sensores de temperatura. Desta forma, faz-se necessário um método eficiente de soldagem. Métodos de soldagem são relatados por diversos pesquisadores desde o século passado: Hart e Elkin [12] propuseram um método no qual o par termoelétrico é acoplado a uma fonte dc e sofre uma descarga por curto circuito, já Hickson [13] cita vários métodos utilizados na confecção de termopares e apresenta um equipamento desenvolvido para soldagem por resistência de termopares, Ghosh et al. [14] relata a soldagem de termopares com controle de corrente elétrica por meio de uma solução eletroquímica, na qual íons são adicionados a solução para obter uma corrente mais intensa. Estes sensores são amplamente usados na indústria para o acompanhamento da temperatura dos processos. Assim, o desenvolvimento de técnicas de soldagem que propiciem um menor custo e maior qualidade na confecção de termopares é desejável. Neste trabalho considera-se uma solda de boa qualidade aquela que apresenta: visualmente, um formato esférico, homogêneo, baixa resistência elétrica, e quando submetida ao microscópio não apresenta fissuras.

A micro soldagem por descarga capacitiva é um dos métodos mais utilizados para a soldagem de ligas de pequena espessura, uma de suas principais características a simplicidade do sistema. Através da junção formada temos um fluxo da corrente elétrica que provoca um aumento de temperatura, de acordo com a lei de Joule, a energia térmica proveniente da colisão entre as cargas elétricas existentes na peça metálica faz com que ocorra uma pequena fusão nas proximidades do eletrodo, produzindo uma mistura líquida homogênea das ligas metálicas que ocupará os espaços vazios na extremidade dos condutores. Essa mistura ao se solidificar forma uma esfera de solda na extremidade dos condutores, resultando na união das ligas metálicas em questão como citado por Hart e Elkin [12] e Hickson [13].

Aparelhos destinados a soldagem de termopares foram desenvolvidos por Zanstra [15] e Orr e Roth [10]. No mercado encontram-se disponíveis equipamentos REALTHERM [16], Amada Miyachi [17] e MVM Welders [18]. No entanto, os equipamentos disponíveis comercialmente e também os desenvolvidos por Zanstra [15] e Orr e Roth [10] apresentam vulnerabilidades no que se refere a produção em larga escala e com alto grau de repetibilidade e alta suscetibilidade a erros de 
operação. Os demais equipamentos apresentam apenas um regulador de tensão e não contam com um processo automático de ajuste da quantidade de energia a ser utilizada, dependendo do tipo e bitola do Termopar.

Ao realizar uma análise de custo, contatou-se que os equipamentos disponíveis comercialmente possuem um custo elevado, atingindo um valor médio de R\$̣ 2520,00, o que por si só justifica o desenvolvimento de novas técnicas e equipamentos de soldagem.

Neste trabalho propõe-se desenvolver um aparelho de baixo custo, automatizado e em atmosfera controlada que possa ser pré-programado para a soldagem de termopares de acordo com seu tipo e bitola, visando minimizar o desperdício de energia e matéria prima, juntamente com a minimização do contato manual no processo de fabricação de termopares e validar uma solda de qualidade.

\section{Materiais e Métodos}

\subsection{Equipamento desenvolvido}

O equipamento para soldagem capacitiva desenvolvido realiza a soldagem de fios metálicos de baixa espessura utilizados na confecção de termopares. O equipamento é composto de uma fonte de tensão contínua simétrica de $31 \mathrm{~V}$ associada a um banco capacitivo de $37600 \mu \mathrm{F}$, um microcontrolador Arduino UNO ${ }^{\circ}$ e um módulo relé que foi utilizado como chave comutadora entre o banco de capacitores e a fonte e para o acionamento da válvula solenoide para injeção de gás inerte.

O processo de carga do banco de capacitores ocorre a partir da fonte de tensão contínua e é monitorada pelo microcontrolador Arduino UNO ${ }^{\circledR}$, por meio da leitura da tensão sobre o banco de capacitores. Para que o microcontrolador efetue a leitura dos valores de tensão no banco de capacitor e, por meio desta, calcule a energia armazenada. Utiliza-se um divisor de tensão, que adequa a tensão no banco de capacitores a valores apropriados para serem lidos pelo Arduino UNO ${ }^{\circledR}$.

O microcontrolador Arduino $\mathrm{UNO}^{\circledR}{ }^{\circledR}$, além de controlar o valor da carga armazenada no banco de capacitores de acordo com a tensão em seus terminais é também o responsável por determinar o valor da carga necessária de acordo com a liga metálica a ser soldada. Para o controle da carga do banco de capacitores fez-se uso de um relé, que é responsável pela conexão entre o banco de capacitores e a fonte de tensão. O relé é necessário para isolar o circuito do microcontrolador do circuito de potência, uma vez que a tensão nos terminais da fonte é muito superior a tensão que o microcontrolador pode suportar (5 V). Um diagrama esquemático do funcionamento do equipamento de soldagem é ilustrado na Figura 1.

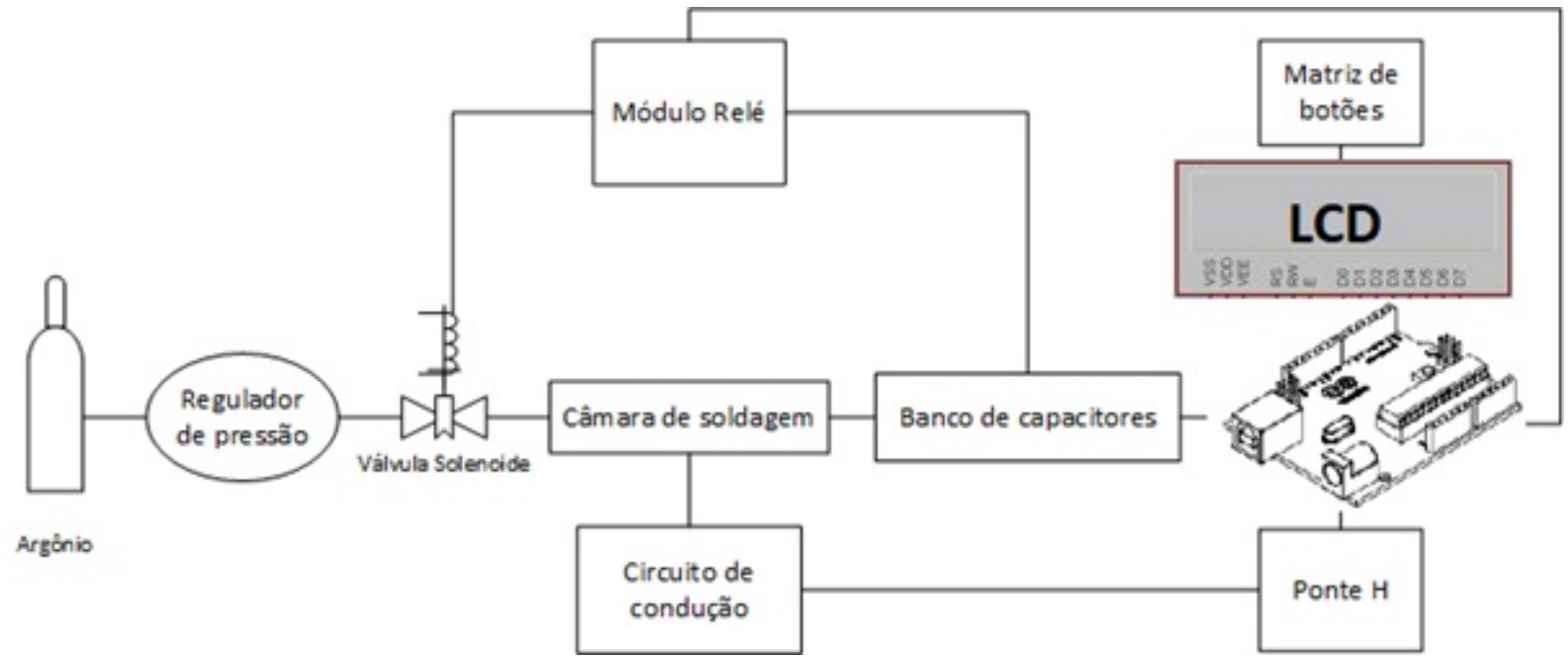

Figura 1. Diagrama do circuito do equipamento de solda.

O banco de capacitores é formado pela associação de oito capacitores em paralelo, cujas capacitâncias são somadas para que a carga necessária para a soldagem seja atingida. Para o circuito foram utilizados capacitores do tipo eletrolítico de $4700 \mu \mathrm{F}$ e $63 \mathrm{~V}$ conectados por meio de um fio de cobre de 2,5 $\mathrm{mm}^{2}$. Quando o banco de capacitores se encontra em plena carga é possível obter uma energia aproximada de 74,62 J.

Para o acoplamento do banco de capacitores ao circuito de carga foi necessário a utilização de um módulo de expansão que também é conhecido como Shield (Placa de Hardware capaz de realizar atividades extras as existentes no Arduino ${ }^{\circledR}$ ). $O$ módulo escolhido possui 2 relés, cada relé possui uma bobina com tensão de operação de $5 \mathrm{~V}$ e corrente de $25 \mathrm{~mA}$. Os contatos do relé operam com corrente de até $10 \mathrm{~A}$. O acionamento é realizado diretamente com a saída digital do Arduino $\mathrm{UNO}^{\circledR}$, pois o módulo Shield já possui um circuito amplificador. 
A fonte de tensão responsável pela alimentação do banco de capacitores é composta de um transformador abaixador de tensão que é responsável por alterar a tensão de alimentação de $127 \mathrm{~V}$ para $24 \mathrm{~V}$. Após a redução da tensão a retificação do sinal alternado proveniente do transformador é realizada por uma ponte retificadora, composta por diodos 1 N4007. Após a retificação do sinal ainda haverá uma característica pulsante no mesmo, necessitando da filtragem do sinal, o que é efetuado por meio de capacitores eletrolíticos de $4700 \mu \mathrm{F}$.

Depois que a tensão proveniente da rede estiver reduzida, retificada e filtrada, ela deve ser regulada, o que é feito utilizando o regulador LM317 no lado positivo e o LM337 no lado negativo. Juntamente com os reguladores foram instalados potenciômetros, que serão responsáveis por criar um divisor de tensão, fazendo com que a saída da fonte seja ajustada a uma tensão desejada. Antes da saída de tensão final da fonte ainda é necessário mais uma filtragem no sinal, a qual será realizada por um par de capacitores eletrolíticos e cerâmicos de $10 \mu \mathrm{F}$ e $100 \mathrm{nF}$ respectivamente. O resultado final é uma fonte de tensão contínua simétrica de $31 \mathrm{~V}$ de amplitude positiva, a qual poderá atingir valores de $62 \mathrm{~V}$ em corrente contínua. A característica simétrica foi escolhida devido à disponibilidade dos componentes no mercado, sendo a forma mais prática de atingir o objetivo do trabalho.

Com o objetivo de criar um ambiente controlado para a soldagem de ligas de pequena espessura com a utilização de um gás de proteção, desenvolveu-se uma câmara de soldagem específica para o equipamento de soldagem de ligas de pequena espessura. A câmara é constituída de um tubo de vidro com diâmetro externo de 3/4" e de $10 \mathrm{~cm}$ de comprimento, aberto em uma das extremidades e com uma redução axial do tamanho de 1/4" na outra. No ponto médio do tubo existe um furo de $4 \mathrm{~mm}$ que transpassa o tubo, na parte superior partindo do furo até a extremidade aberta existe um corte cuja espessura coincide com o diâmetro do furo, e que liga o furo até a extremidade aberta. Na extremidade inferior o furo é utilizado para que uma escova de carvão seja inserida dentro do tubo, a escova tem a função de eletrodo negativo e fica abrigado no interior da câmara de soldagem.

Na extremidade do tubo, onde há a redução de 1/4" foi acoplada uma mangueira de igual diâmetro. A mangueira é conectada a uma válvula solenoide que é ativada pelo segundo relé do módulo relé, a válvula solenoide é conectada ao regulador de pressão de um cilindro que contém gás inerte para a proteção do processo de soldagem, momentos antes da solda ser realizada, o micro controlador Arduino ${ }^{\circledR}$ aciona a válvula solenoide por meio de sua saída digital conectada ao módulo relé, após o acionamento da válvula e o gás inerte preenche a câmara de soldagem e expulsa o ar atmosférico, tornando o ambiente propício para uma soldagem sem a inclusão de partículas externas e reduzida oxidação.

O sistema de condução para a soldagem foi realizado com a utilização de motores de passo em uma bandeja deslizante. O mecanismo característico empregado é proveniente de motores de passo utilizados para movimentar o laser do leitor de Cd's e DVD's de computadores, a escolha de tal sistema se justifica pela precisão nos movimentos do motor de passo, onde é possível o controle de posicionamento pelo ângulo de rotação do motor, obtendo maior precisão no posicionamento.

Para controlar o motor de passo que possui 4 polos foi necessário um módulo de expansão do microcontrolador Arduino ${ }^{\circledR}$, conhecido como ponte $\mathrm{H}$, que utiliza o circuito integrado L293D.

A bandeja deslizante onde anteriormente era abrigado o laser de leitura do sistema de CD/DVD foi modificada para a implantação de sistemas de garras do tipo jacaré, as quais terão a função de afixar as ligas metálicas que serão soldadas. 0 sistema deslizante possui uma amplitude total de 200 passos, que é equivalente a $370 \mathrm{~mm}$, podendo ser regulada para menores distâncias de acordo com a necessidade.

\subsection{Cálculo da quantidade de energia}

Para a obtenção dos valores de energia necessários para a solda dos termopares foram realizados cálculos da conservação da massa e da energia envolvidos no processo. Uma solda de boa qualidade deve unir de forma que garanta o bom contato elétrico entre os dois materiais, mantendo suas propriedades químicas e físicas. Para isso é necessário que a energia gerada seja suficiente para fundir as ligas metálicas [19]. Para que tal fenômeno aconteça os cálculos devem levar em consideração as propriedades termodinâmicas.

As propriedades requeridas no cálculo da quantidade de energia necessária para a realização da solda são: calores específicos, calores latentes, densidades e temperatura de fusão das ligas metálicas que constituem os termopares [20].

O equipamento foi dimensionado para três bitolas de ligas metálicas a serem soldadas, sendo elas de 24 AWG, 26 AWG e 32 AWG. Valores de referência para indicar um raio da esfera de solda satisfatório foram estipuladas por meio de experimentos, sendo eles de 2,4 vezes o diâmetro do fio para a bitola de 32 AWG e de 1,9 vezes para as bitolas de 26 AWG e 1,8 de 24 AWG. Com os valores de referência para o raio da esfera de solda gerada. Esse resultado será utilizado para os cálculos da quantidade de energia necessária para soldagem de cada termopar.

As Equações 1, 2 e 3 demonstram o balanço de energia realizado para que fosse determinado o montante de energia necessário para a fusão das ligas metálicas envolvidas. Para efeitos de cálculos foram desprezadas perdas para o meio externo.

$\mathrm{Q}_{\text {Total }}=\mathrm{Q}_{\text {Sensível }}+\mathrm{Q}_{\text {Latente }}$

$\mathrm{Q}_{\mathrm{Total}}=\mathrm{mc} \Delta \mathrm{T}+\mathrm{mL}$ 
$\mathrm{Q}_{\mathrm{Total}}=\mathrm{V} \rho \mathrm{c} \Delta \mathrm{T}+\mathrm{V} \rho \mathrm{L}$

em que: $\mathrm{V}=$ Volume da esfera de solda; $\rho=$ Densidade do material; $\mathrm{c}=$ Calor específico do material; $\Delta \mathrm{T}=\mathrm{Gradiente}$ de temperatura; $L$ = Calor latente de fusão, ou latência.

Ao substituir as propriedades de cada material na Equação 3 obtém-se os dados dispostos na Tabela 1.

Tabela 1. Energias necessária para a fusão (J)

\begin{tabular}{cccc}
\hline \multirow{2}{*}{ Elemento } & \multicolumn{3}{c}{ Bitola } \\
\cline { 2 - 4 } & 32 AWG & 26 AWG & 24 AWG \\
\hline Cobre & 2,615 & 10,464 & 17,842 \\
Constantan & 3,037 & 12,154 & 20,725 \\
Alumel & 4,164 & 16,662 & 28,411 \\
Cromel & 3,815 & 15,266 & 26,020 \\
\hline
\end{tabular}

Os compostos Alumel, Cromel e Constantan foram considerados como sendo compostos por $95 \% \mathrm{Ni}$ e $5 \% \mathrm{Al}, 90 \% \mathrm{Ni}$ e $10 \% \mathrm{Cr}, 55 \% \mathrm{Cu}$ e $45 \%$ Ni respectivamente.

Considerando a composição de cada liga metálica utilizada nos diferentes tipos de termopar e suas respectivas bitolas, obtém-se a quantidade de energia necessárias para a soldagem dos termopares, que são apresentadas na Tabela 2.

Tabela 2. Energia de soldagem por tipo de termopar (J).

\begin{tabular}{cccc}
\hline \multirow{2}{*}{ Tipo de Termopar } & \multicolumn{3}{c}{ Bitolas Termopar } \\
\cline { 2 - 4 } & 24 AWG & 26 AWG & 32 AWG \\
\hline E & 46,755 & 27,420 & 6,852 \\
K & 54,441 & 31,928 & 7,978 \\
T & 38,567 & 22,618 & 5,65 \\
\hline
\end{tabular}

Para que o Arduino ${ }^{\circledR}$ possa controlar a energia que será armazenada no banco de capacitores, afim de garantir que os valores corretos de energia sejam desprendidos no processo de soldagem dos diferentes tipos e tamanhos de termopares, foi realizado, por meio da Equação 4, o cálculo da quantidade de energia que o banco de capacitores deve armazenar de acordo com a tensão em seus terminais. O resultado deste cálculo é apresentado na Tabela 3.

$\mathrm{V}=\sqrt{\frac{2 \mathrm{w}}{\mathrm{C}}}$

onde: $\mathrm{V}=$ Tensão $(\mathrm{V}) ; \mathrm{w}=$ Energia $(\mathrm{J}) ; \mathrm{C}=$ Capacitância $(37600 \mu \mathrm{F})$.

Tabela 3. Tensão necessária para solda (V).

\begin{tabular}{cccc}
\hline \multirow{2}{*}{ Tipo de Termopar } & \multicolumn{3}{c}{ Bitolas Termopar } \\
\cline { 2 - 4 } & 24 AWG & 26 AWG & 32 AWG \\
\hline E & 50 & 38 & 19 \\
K & 54 & 41 & 20 \\
T & 49 & 35 & 17 \\
\hline
\end{tabular}

\subsection{Programação do Arduíno ${ }^{\circledR}$ e soldagem}

Nesta etapa foram convertidos os valores calculados teoricamente para valores compatíveis e reconhecidos pelo Arduino ${ }^{\circledR}$ e que serão utilizados para a realização da soldagem dos termopares.

Os valores de tensão que deverão ser monitorados pelo Arduino ${ }^{\circledR}$ excedem em grande escala os valores aceitos pelo micro controlador, sendo necessário desenvolvimento de um circuito, que realize a conversão das tensões no banco de capacitor para valores que variem de 0 a 5V. Para tal fim foi desenvolvido o circuito ilustrado na Figura 2, o qual faz uso de um divisor de tensão com resistores de $1 \mathrm{M} 5 \Omega$ e $100 \mathrm{~K} \Omega$. 


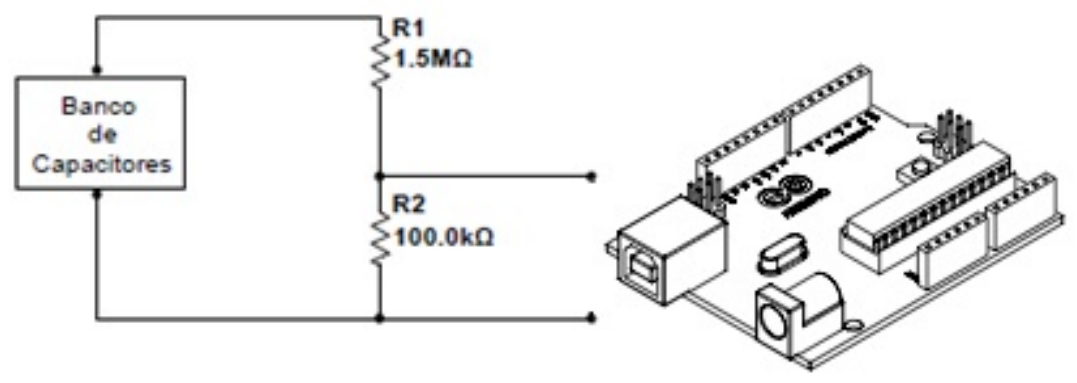

Figura 2. Circuito divisor de tensão do banco de capacitores.

Realizando a conversão dos valores de tensão lido no banco de capacitores para a escala de 0 a $5 \mathrm{~V}$ que será lida pela porta analógica do Arduino ${ }^{\circledR}$, obtêm-se os dados dispostos na Tabela 4.

Tabela 4. Tensão apresentada no divisor de tensão (V).

\begin{tabular}{cccc}
\hline \multirow{2}{*}{ Tipo de Termopar } & \multicolumn{3}{c}{ Bitolas do Termopar } \\
\cline { 2 - 4 } & 24 AWG & 26 AWG & 32 AWG \\
\hline E & 3,1 & 2,3 & 1,1 \\
K & 3,3 & 2,5 & 1,2 \\
T & 2,8 & 2,1 & 1 \\
\hline
\end{tabular}

Ao realizar a leitura o Arduino ${ }^{\circledR}$ converte o sinal de sua entrada analógica em valores que irão variar de 0 a 1023 , sendo 0 para uma tensão de $0 \mathrm{~V}$ e $1023 \mathrm{~V}$ para uma tensão de $5 \mathrm{~V}$, de forma linear, sendo necessária a criação de uma constante de conversão para as unidades, a qual será igual a $4,8828 \times 10^{-3}$. Convertendo-se os valores da tensão para valores de representação numérica no Arduino ${ }^{\circledR}$ obtêm-se os dados apresentados na Tabela 5.

Tabela 5. Tensão convertida para variável de programação.

\begin{tabular}{cccc}
\hline \multirow{2}{*}{ Tipo de Termopar } & \multicolumn{3}{c}{ Bitolas Termopar } \\
\cline { 2 - 4 } & 24 AWG & 26 AWG & 32 AWG \\
E & 627 & 480 & 240 \\
K & 679 & 518 & 259 \\
T & 569 & 436 & 218 \\
\hline
\end{tabular}

Desta forma sabendo-se o tipo e a bitola do termopar pode-se ajustar o equipamento para uso, o que é feito em um painel de botões.

O acoplamento dos eletrodos de soldagem do aparelho onde serão fixadas as ligas metálicas a serem soldadas devem ser realizadas por meio de um dispositivo que possibilite a transmissão de energia do banco de capacitores para as ligas metálicas que serão soldadas. Para a condução da energia do banco de capacitores até as ligas metálicas foi escolhido um condutor de cobre de $4 \mathrm{~mm}^{2}$ no intuito de tornar a resistência a condução a menor possível.

A obtenção de uma solda de boa qualidade está diretamente ligada a uma boa fixação das ligas metálicas ao terminal de soldagem, que foi realizada com uma garra do tipo jacaré que tem a função de manter as ligas metálicas o mais firmes possível para a soldagem. A pinça foi conectada na extremidade positiva do equipamento de soldagem, sendo a extremidade negativa disposta em uma escova de carvão proveniente de motores elétricos de indução. A escolha do carvão deve-se ao fato de que ele apresenta uma baixa resistência elétrica e um elevado ponto de fusão, características requeridas para que no processo de soldagem das ligas metálicas não seja inserido um terceiro componente na solda. As Figuras 3-5 ilustram o processo de soldagem das ligas, sistema de condução para soldagem e apresentam o layout interno e externo do aparelho respectivamente. 


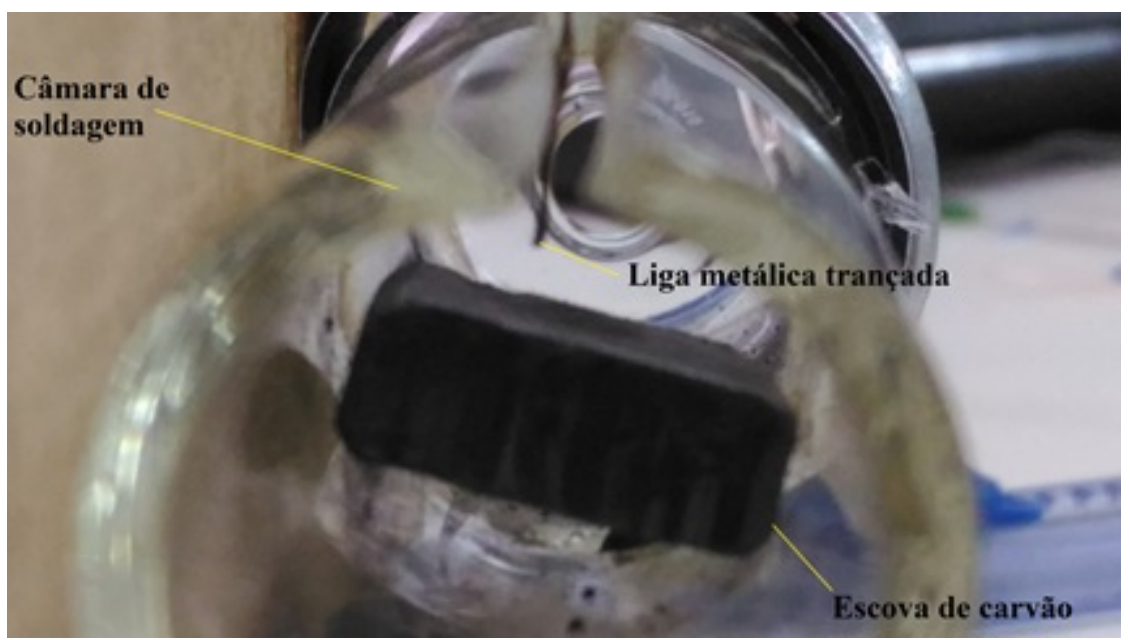

Figura 3. Dispositivo de solda em funcionamento.

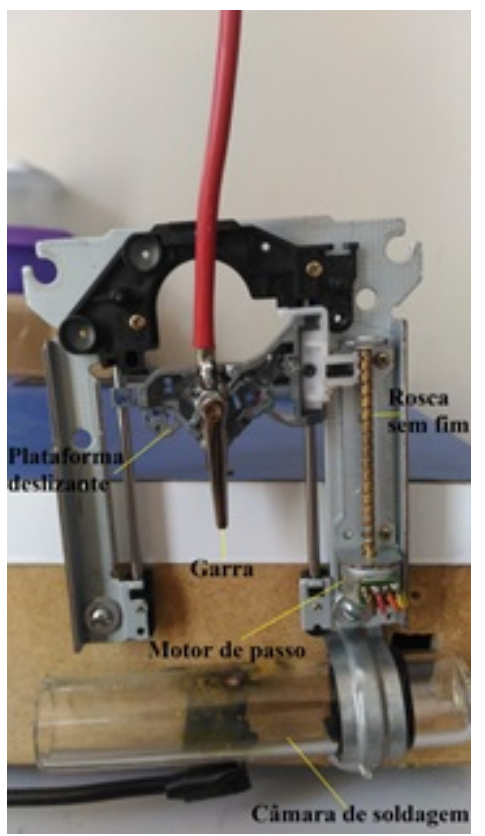

Figura 4. Sistema de condução para soldagem.

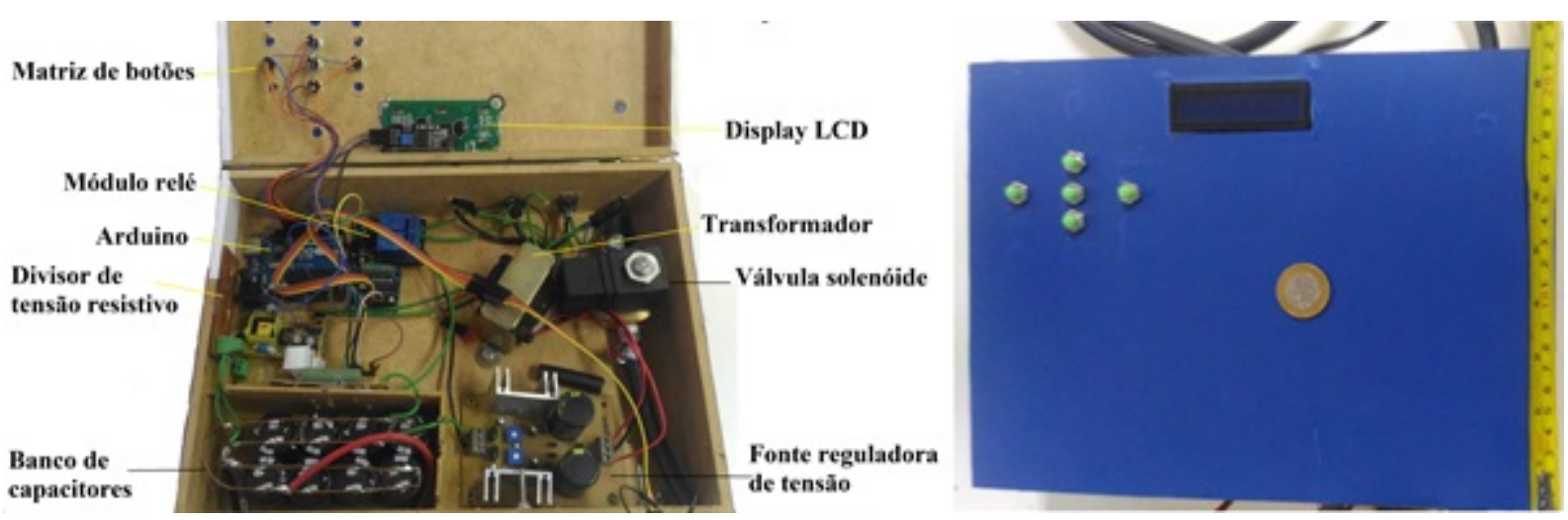

Figura 5. Layout interno/externo do aparelho de solda.

\subsection{Metodologia}

O procedimento de soldagem é realizado após as ligas metálicas que irão compor o termopar serem trançadas entre si para obter a maior proximidade possível entre as extremidades que serão unidas, com a finalidade de a descarga capacitiva 
provocar a união estável das duas ligas metálicas. A Figura 6 mostra um par metálico de um termopar tipo T antes e depois da soldagem dos seus terminais.

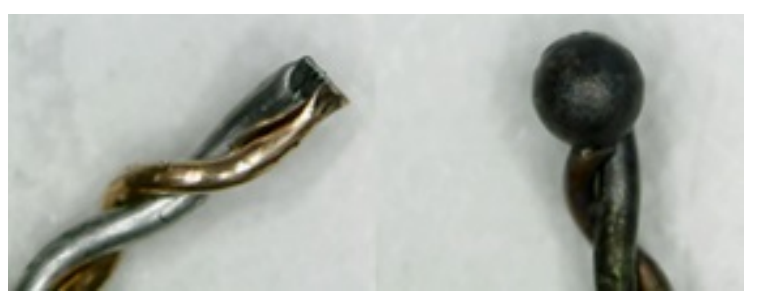

Figura 6. Pares metálicos do termopar tipo T antes e depois da soldagem.

Os experimentos foram realizados com 3 tipos de termopares de 3 bitolas diferentes. Os tipos testados foram $E$, $T$ e $K$, os termopares tipo T foram testados com as bitolas 24, 26 e 32 AWG, já os termopares tipo E e $K$ foram testados apenas com a bitola de 32 AWG.

Os pares metálicos foram feitos com tamanho total de 3,5 cm e tiveram uma de suas extremidades trançados por 1,5 cm. O posicionamento do par metálico no equipamento foi feito de tal forma que as ligas metálicas tivessem o posicionamento de aproximadamente $50 \%$ do diâmetro da câmara de solda na extremidade da garra, uma vez que apenas 2 mm de comprimentos são consumidos durante a soldagem.

A soldagem foi realizada na câmara de soldagem desenvolvida para o equipamento a qual foi preenchida por gás argônio $5 \mathrm{~s}$ antes da descarga capacitiva e teve seu fluxo encerrado $2 \mathrm{~s}$ após a identificação pelo microcontrolador da descarga total do banco de capacitores. O tempo total estimado para liberação do gás foi de $10 \mathrm{~s}$. Levando em conta os dados fornecidos pelo fabricante do regulador de pressão acoplado ao cilindro de gás, estima-se que a cada procedimento de soldagem foram utilizados 5,54 g de gás argônio sob condições de 1 atm e $27,5^{\circ} \mathrm{C}$. O gás argônio utilizado é disponível comercialmente em uma pureza de $99 \%$ argônio e $1 \%$ de demais gases existentes na atmosfera terrestre.

Os parâmetros de qualidade estabelecidos foram: o aspecto visual das soldas, descarga total da energia estimada, resistência elétrica e curvas de calibração.

\subsection{Análise de custo}

O equipamento desenvolvido possui a proposição de realizar uma solda de qualidade a um baixo custo de produção, uma vez que já foram apresentados os custos de equipamentos comercialmente disponíveis, apresenta-se nesta seção uma estimativa dos custos envolvidos no desenvolvimento do equipamento de soldagem. A Tabela 6 apresenta os componentes que compõe o equipamento e seu respectivo custo.

Os custos envolvidos no desenvolvimento do equipamento são aproximadamente $16 \%$ do custo total de um equipamento disponível comercialmente. Ressalta-se que estes são custos estimados para a produção de um único equipamento, e que sua produção em larga escala pode reduzir consideravelmente os custos.

Tabela 6. Estimativa de custo.

\begin{tabular}{cc}
\hline Componente & Custo (R\$) \\
\hline Diodos & 1,50 \\
Capacitor eletrolítico fonte & 10,00 \\
Capacitor poliéster Fonte & 2,00 \\
Trimpot & 8,00 \\
Conectores de parafuso & 1,60 \\
Capacitores Banco & 40,00 \\
Arduino uno ${ }^{\circledR}$ & 35,00 \\
Módulo Relé 2 canais & 10,00 \\
Módulo L293D & 16,00 \\
Placa de fenolite & 10,00 \\
Display LCD I2c & 18,00 \\
Botões pulsantes & 2,50 \\
Válvula de gás & 205,00 \\
Transformador & 50,00 \\
Total & $\mathbf{4 0 9 , 6 0}$ \\
\hline
\end{tabular}




\section{Resultados e Discussão}

Os resultados referentes ao termopar tipo T, das bitolas 32, 26 e 24 AWG são apresentados na Figura 7.

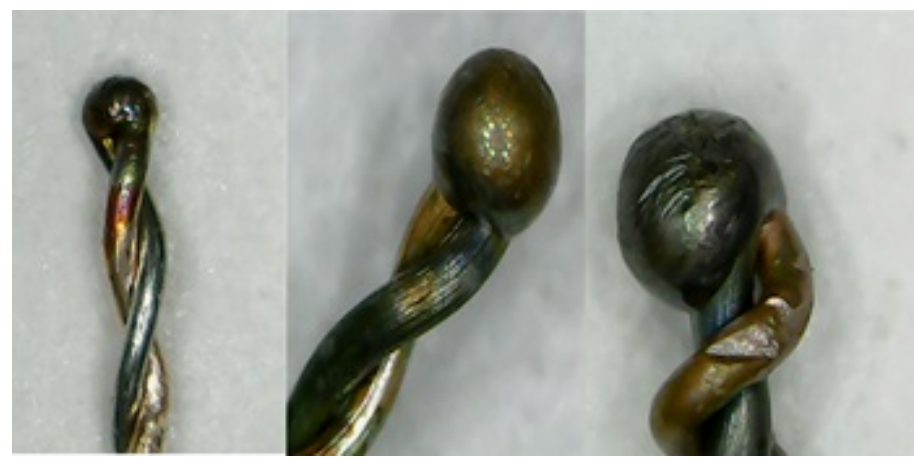

Figura 7. Termopares tipo T bitola 32, 26 e 24 AWG respectivamente.

A solda dos termopares tipo E e K de bitola de 32 AWG são apresentadas pela Figura 8.

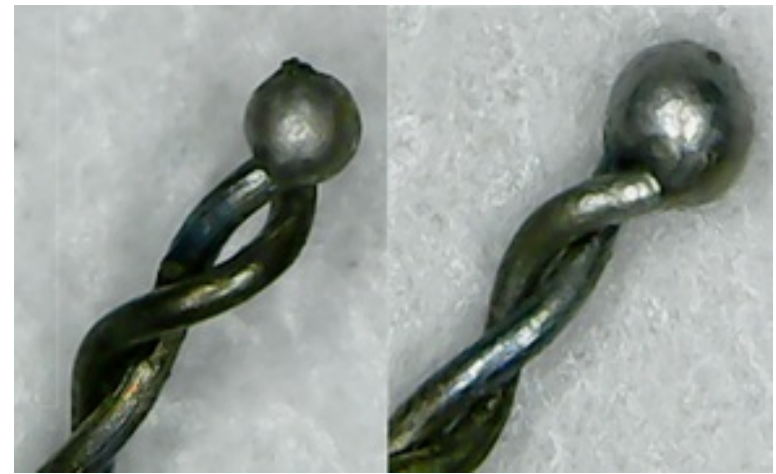

Figura 8. Termopares tipo E e K, bitola 32 AWG respectivamente.

Ao realizar a análise das soldas no microscópio, foram observadas características como: formato, tamanho e homogeneidade. Os termopares tipo T apresentaram esferas de solda compatíveis com a bitola dos condutores que o compõe e também apresentaram uma homogeneidade na esfera de solda, o que é evidenciado pela coloração uniforme e proporcional as cores das ligas metálicas utilizadas.

Ao analisar o aspecto visual da solda dos termopares, os termopares tipo E e K apresentaram uma esfera de solda homogênea devido a coloração uniforme e possuem tamanho compatível com as bitolas dos condutores metálicos. Quanto ao aspecto da coloração, as esferas apresentam oxidação mínima devido a utilização do gás argônio como gás de proteção, a pequena característica de oxidação é ocasionada pela mínima presença de oxigênio atmosféricos e a uma pequena porcentagem de oxigênio presente no cilindro de gás argônio, uma vez que sua pureza é de 99\%.

Os resultados de homogeneidade são confirmados quando analisados aspectos de redondeza e esfericidade. Com a utilização do software ImageJ foi possível a determinação da circularidade, esfericidade e redondeza, os dados são apresentados na Tabela 7.

Tabela 7. Circularidade, esfericidade e redondeza.

\begin{tabular}{cccc}
\hline Termopar - Tipo & Circularidade & Esfericidade & Redondeza \\
\hline E - 32 & 0,829 & 1 & 0,939 \\
K - 32 & 0,856 & 1 & 0,907 \\
T - 32 & 0,906 & 1 & 0,965 \\
T - 24 & 0,851 & 0,9927 & 0,841 \\
T - 26 & 0,912 & 0,99 & 0,913 \\
\hline
\end{tabular}

Os valores obtidos atestam que as soldas obtidas possuem um formato esférico quase perfeito e suas dimensões são compatíveis com os balanços de massa e energia realizados. 
Para validar que o modelo proposto de soldagem de termopares é eficiente quanto à quantidade de energia liberada no momento da soldagem foram monitorados os valores de tensão nos terminais do banco de capacitores durante o processo de carga, para garantir que as tensões calculadas teoricamente sejam armazenadas no banco de capacitores e que sejam totalmente utilizadas no processo de soldagem. As Figura 9 e 10 apresentam as curvas de carga do banco de capacitores durante o processo de soldagem dos termopares.

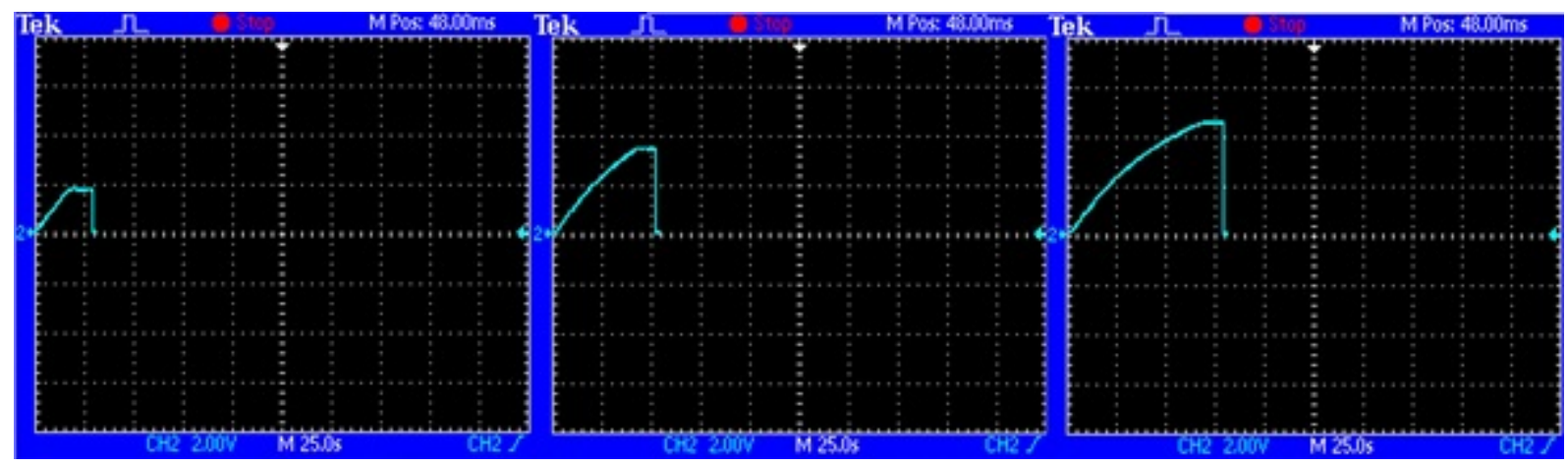

Figura 9. Curvas de carga e descarga termopares tipo T bitolas 24, 26 e 32 AWG respectivamente.

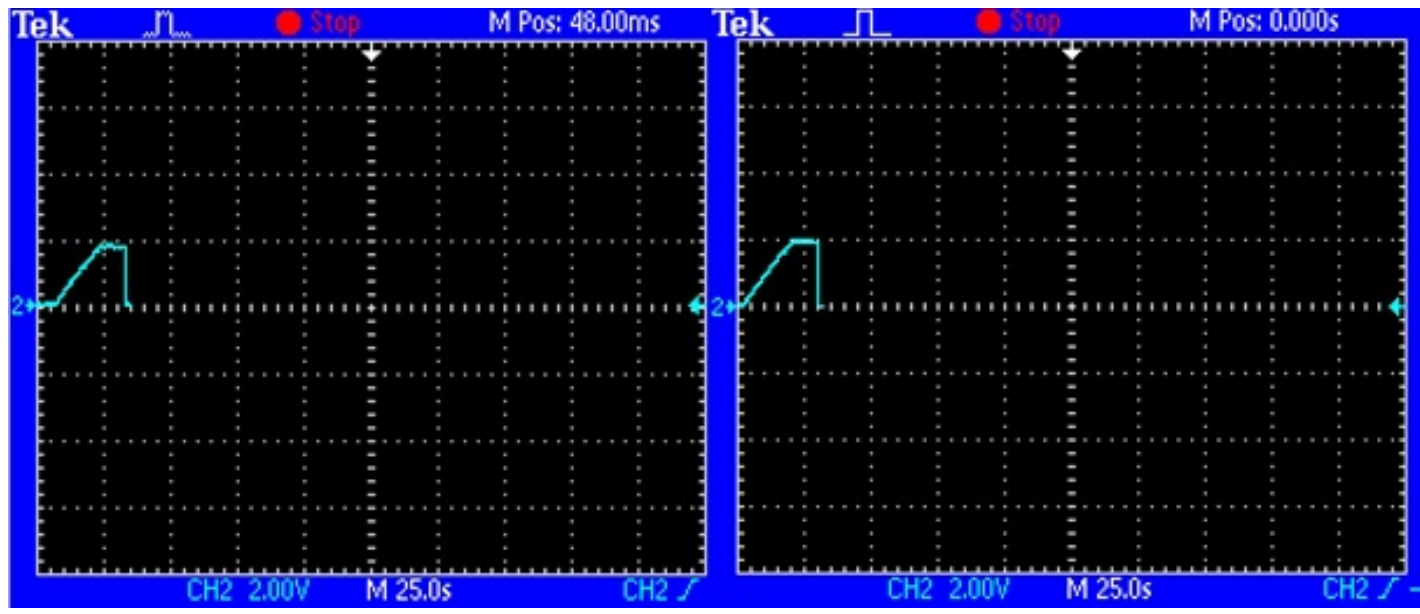

Figura 10. Curvas de carga termopares tipo E e K, bitola 32 AWG respectivamente.

Ao analisar os dados dispostos nas figuras, pode-se concluir que o valor teórico de tensão estimado foi totalmente carregado no banco de capacitores e totalmente utilizado na descarga capacitiva de soldagem. A carga do banco de capacitores foi aproximadamente exponencial como esperado e a descarga foi abrupta num intervalo de tempo muito pequeno, variando entre $200 \mathrm{~ms}$ e $400 \mathrm{~ms}$ de acordo com dados obtidos no osciloscópio. As curvas de descarga indicam que toda a energia foi utilizada no momento em que a liga metálica toca a escova de carvão no interior da câmara de solda. Foram realizadas medidas do valor de tensão, usando-se um multímetro de precisão, o valor obtido foi o mesmo (ou extremamente próximo, dentro da faixa de erro do equipamento de medida) ao teórico.

Além do aspecto visual, foi estabelecido com padrão de qualidade das soldas nos termopares a resistência elétrica do par metálico, os resultados foram submetidos a um multímetro de bancada Tektronix ${ }^{\circledR}$, com precisão de 4 casas decimais e acurácia de $15 \mathrm{ppm}(15 \mathrm{~m} \Omega$ ) para a determinação das resistências elétricas. As medidas foram realizadas na extremidade aberta dos pares metálicos. A Tabela 8 mostra os valores de resistência obtidos.

Tabela 8. Resistência elétrica dos termopares.

\begin{tabular}{|c|c|c|c|c|c|c|c|c|c|c|c|}
\hline \multicolumn{12}{|c|}{ Resistência $(\Omega)$} \\
\hline Tipo Bitola & & & & & & Amostra & & & & & \\
\hline $\mathrm{T}-32$ & 1,7405 & 1,7258 & 1,8199 & 1,7942 & 1,7538 & 1,7473 & 1,7431 & 1,7994 & 1,6166 & 1,8553 & 1,7622 \\
\hline $\mathrm{T}-26$ & 1,3865 & 1,3038 & 1,3595 & 1,3390 & 1,3423 & 1,3577 & 1,3284 & 1,3542 & 1,3778 & 1,3306 & 1,3000 \\
\hline $\mathrm{T}-24$ & 1,2612 & 1,3048 & 1,2784 & 1,2880 & 1,2815 & 1,2803 & 1,2885 & 1,3078 & 1,2942 & 1,2905 & 1,2930 \\
\hline$E-32$ & 2,1472 & 1,7738 & 2,1407 & 2,0267 & 1,9094 & 2,0887 & 2,1736 & 2,3145 & 2,1841 & 2,1270 & 2,2066 \\
\hline$K-32$ & 1,9305 & 1,7755 & 1,8601 & 1,9714 & 1,9964 & 1,9317 & 1,7261 & 1,9901 & 2,053 & 1,9000 & 1,9010 \\
\hline
\end{tabular}


Ao analisar os dados de resistência elétrica, constata-se que as resistências seguem a 2a lei de Ohm, pois ocorre a redução da resistência elétrica dos pares metálicos com o aumento da secção transversal do condutor metálico que compõe o termopar. Os valores medidos apresentam pequenas variações da resistência elétrica entre as amostras de cada tipo, o que confirma a repetibilidade das soldas.

Testes de calibração foram realizados e as curvas comparadas por meio de uma curva de tendência linear, as quais representam o comportamento de um termopar em seu range de operação. As respectivas curvas de calibração em um intervalo de temperatura de 0 a $90{ }^{\circ} \mathrm{C}$ são apresentadas na Figura 11.

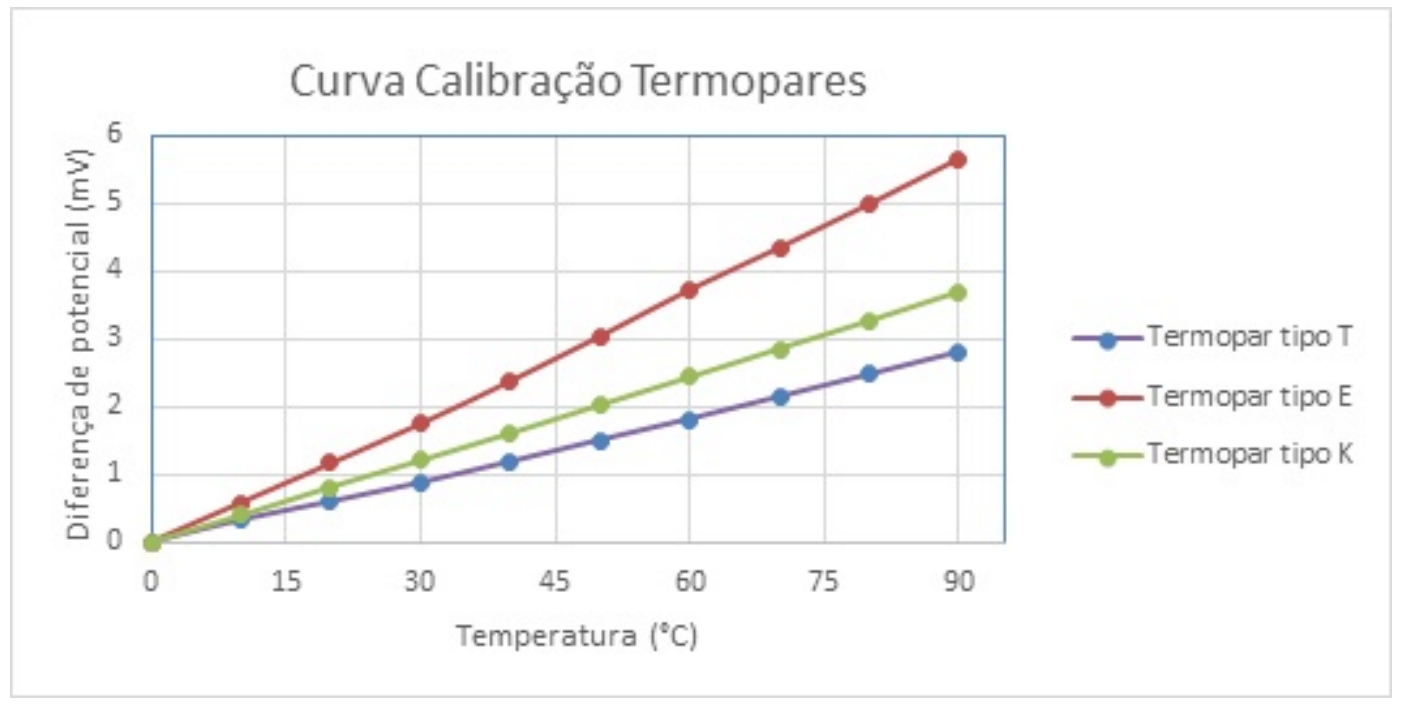

Figura 11. Curva de calibração dos termopares.

Ao fazer uma análise nas curvas, é possível observar que todas possuem um coeficiente angular com variações mínimas, indicando que o coeficiente de Seebeck é constante no range de temperatura analisado, o que comprova a qualidade dos termopares fabricados de acordo com a lei da termoelétrica de Seebeck. O intervalo de temperatura de 0 a $90{ }^{\circ} \mathrm{C}$ foi escolhido devido a praticidade de calibração com termômetros de referência em um banho termostático com água. Devido à restrição de equipamentos (fornalha) e laboratório (equipamentos de referência para calibração de altas temperaturas) para que fossem realizados experimentos com temperaturas maiores o trabalho se restringiu a este range de temperatura. As medidas foram realizadas em banho ultra termostático com aquecimento em rampa, partido da referência $0^{\circ}$ (água e gelo) até $90{ }^{\circ} \mathrm{C}$, sempre utilizando como referências um termômetro.

A comparação dos valores de tensão com valores representados por uma curva de tendência linear, juntamente com o coeficiente de correlação $\left(R^{2}\right)$ obtém-se as representações gráficas apresentadas nas Figuras 11 a 13.

A Figura 12 que indica a curva de calibração do termopar tipo E de bitola de 32 AWG apresenta uma similaridade muito grande com a curva de tendência linear, a qual apresenta um coeficiente de correlação $\left(R^{2}\right)$ de 0,99 o que indica um alto padrão de qualidade e precisão. $O$ erro percentual relativo calculado entre a curva de tendência linear e as medidas obtidas desprezando-se o ponto zero foi de $1,93 \%$, o que representa uma acuracidade média de $1,73{ }^{\circ} \mathrm{C}$ no intervalo da curva de calibração, valor muito próximo ao referencial de tolerância de $1,7^{\circ} \mathrm{C}$ de acordo com a ASTM E230 [21].

A Figura 13 que indica a curva calibração do termopar tipo $\mathrm{K}$ de bitola de 32 AWG também apresenta uma grande afinidade com a curva de tendência linear, na qual resulta um coeficiente de correlação $\left(R^{2}\right)$ de 0,99 , o que indica um padrão de qualidade e precisão próximo aos referenciados pela norma ASTM E230 [21], que é de $2,2{ }^{\circ} \mathrm{C}$. O erro percentual relativo calculado entre a curva de tendência linear e as medidas obtidas desprezando-se o ponto zero foi de 3,4\%, o que representa uma acuracidade média de $3,06^{\circ} \mathrm{C}$ no intervalo da curva de calibração.

A Figura 14 apresenta a curva de calibração do termopar tipo T de bitola 26 AWG, quando comparada com a curva de tendência linear apresenta um alto coeficiente de correlação $\left(R^{2}\right) 0,99$, também indicando um padrão de qualidade e precisão do termopar próximo aos referenciados pela norma ASTM E230 [21], que é de $1{ }^{\circ} \mathrm{C}$. O erro percentual relativo calculado entre a curva de tendência linear e as medidas obtidas desprezando-se o ponto zero foi de $1,93 \%$, o que representa uma acuracidade média de $1,73^{\circ} \mathrm{C}$ no intervalo da curva de calibração. 


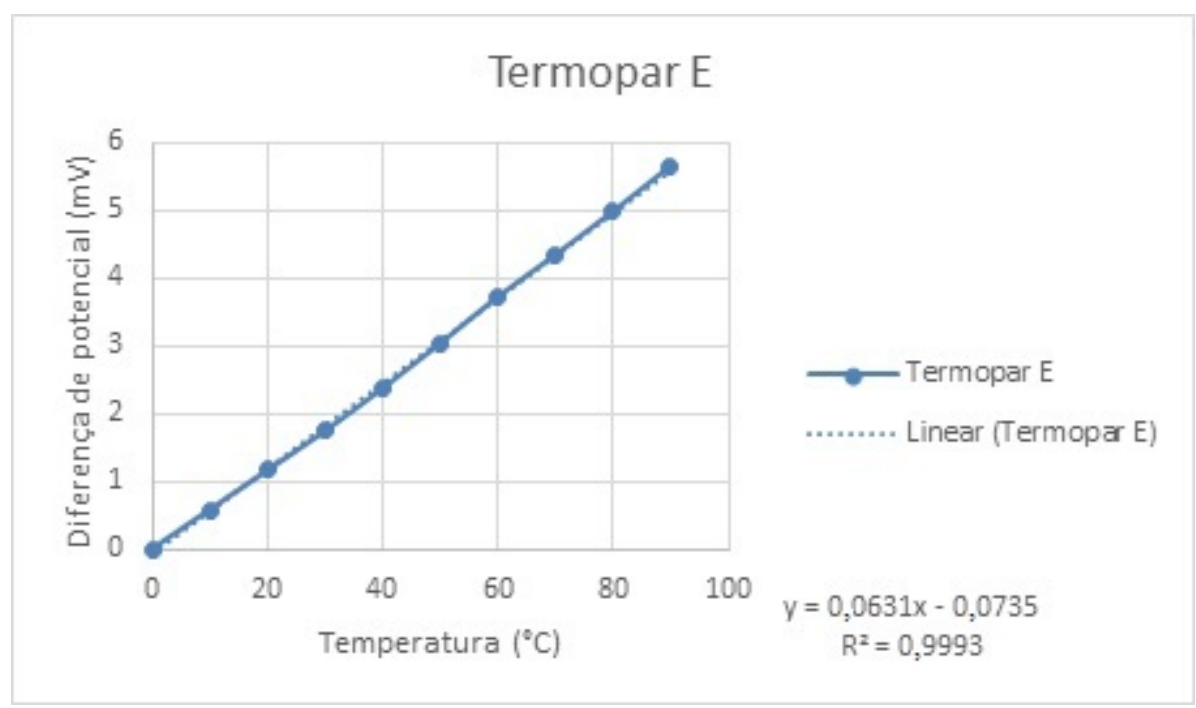

Figura 12. Comparação das curvas de calibração do termopar tipo E bitola 32 AWG.

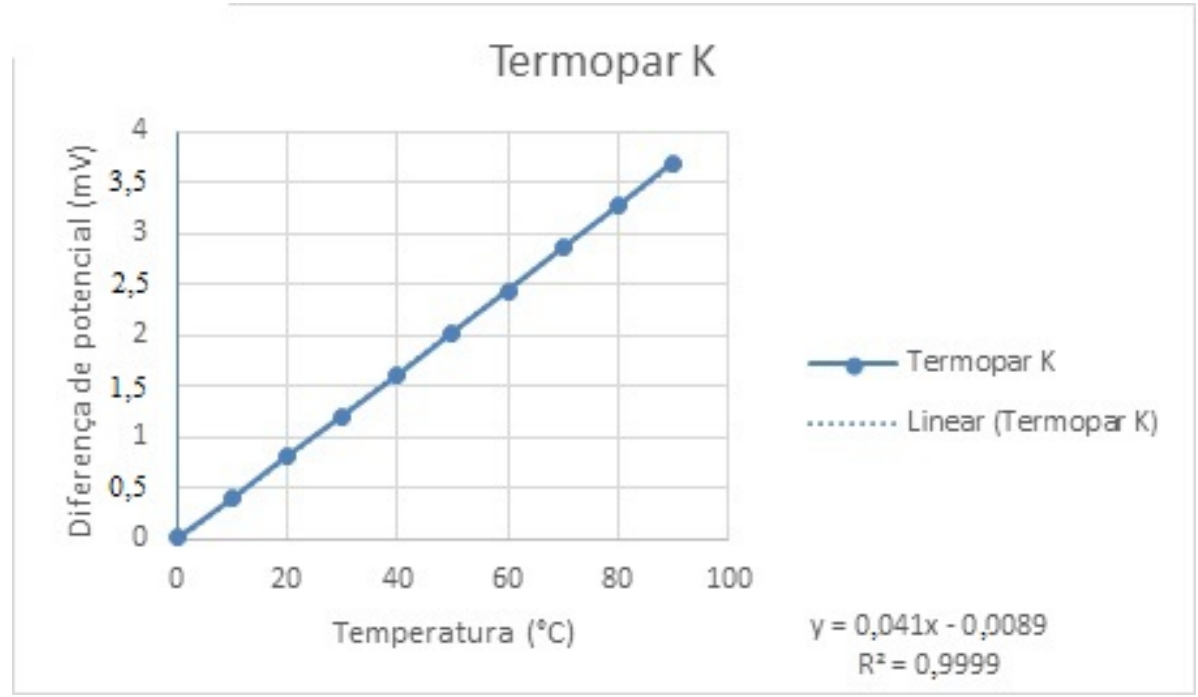

Figura 13. Comparação das curvas de calibração do termopar tipo K bitola 32 AWG.

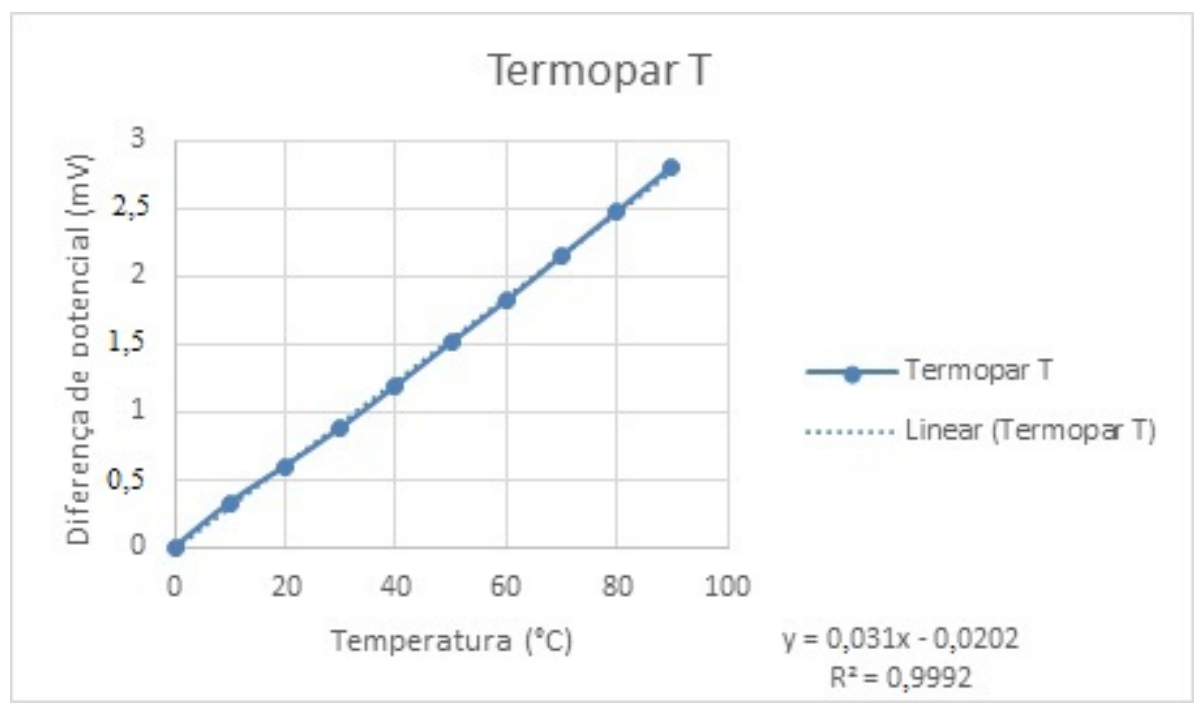

Figura 14. Comparação das curvas de calibração do termopar tipo T bitola 26 AWG. 


\section{Conclusões}

Apresentou-se aqui o desenvolvimento e utilizações de um equipamento para soldagem de metais para a fabricação de termopares. Este equipamento é de manuseio fácil conforme a descrição. Este equipamento foi projetado para descarregar a energia suficiente para realização da solda para cada tipo de liga-metálica e sua bitola.

Os termopares confeccionados foram de boa qualidade, com relação ao aspecto visual das soldas. Os resultados obtidos com base na curva de calibração dos termopares testados possuem resultados condizentes com termopares de boa qualidade, apresentando uma curva praticamente linear e erro médio comparável a equipamentos disponíveis comercialmente. As resistências elétricas dos pares metálicos analisados apresentaram uma pequena variação e baixos valores de resistência elétrica e as curvas de descarga do banco de capacitores apresenta uma descarga abrupta da quantidade de energia estimada necessária para a união do par metálico.

\section{Agradecimentos}

Este trabalho foi realizado com o apoio da Coordenação de Aperfeiçoamento Pessoal de nível Superior - Brasil (CAPES) Código de financiamento 001.

\section{Referências}

[1] Tohmyoh H, Imaizumi T, Hayashi H, Saka M. Welding of Pt nanowires by Joule heating. Scripta Materialia. 2007;57(10):953-956. http://dx.doi.org/10.1016/j.scriptamat.2007.07.018.

[2] Peng Y, Cullis T, Inkson B. Bottom-up nanoconstriction by the welding of individual metallic nanoobjects using nanoscale solder. Nano Letters. 2009;9(1):91-96. http://dx.doi.org/10.1021/nl8025339. PMid:19072096.

[3] Kim SJ, Jang D-J. Laser-induced nanowelding of gold nanoparticles. Applied Physics Letters. 2005;86(3):033112. http://dx.doi.org/10.1063/1.1856139.

[4] Hu A, Peng P, Alarifi H, Zhang XY, Guo JY, Zhou Y, et al. Femtosecond laser welded nanostructures and plasmonic devices. Journal of Laser Applications. 2012;24(4):042001. http://dx.doi.org/10.2351/1.3695174.

[5] Kumar S, Wu CS, Padhy GK, Ding W. Application of ultrasonic vibrations in welding and metal processing: a status review. Journal of Manufacturing Processes. 2017;26:295-322. http://dx.doi.org/10.1016/j.jmapro.2017.02.027.

[6] Houldcroft RL. Welding process technology. London: Cambridge University Press; 1979. p. 1-15.

[7] Tatagiba LC, Gonçalves RB, Paranhos R. Tendências no desenvolvimento de gases de proteção utilizados na soldagem MIG/MAG. Soldagem e Inspeção. 2012;17(3):218-228. http://dx.doi.org/10.1590/\$0104-92242012000300006.

[8] University of Cambridge. Thermoelectric materials for thermocouples. Cambridge; 2016. [acesso em 11 ago. 2016]. Disponível em: http://www.msm.cam.ac.uk/utc/thermocouple/pages/ThermocouplesOperatingPrinciples.html

[9] Wang TP. Thermocouple materials. In: ASM International. ASM handbook. Vol. 2. Materials Park: ASM; 1990.

[10] Orr G, Roth M. Safe and consistent method of spot-welding platinum thermocouple wires and foils for high temperature measurements. The Review of Scientific Instruments. 2012;83(8):084901. http://dx.doi.org/10.1063/1.4746383. PMid:22938323.

[11] CAPGO. Thermocouple theory. 2013. [acesso em 17 dez. 2013]. Disponível em: www.capgo.com/Resources/Temperature/Thermocouple/Thermocouple.htm

[12] Hart ED, Elkin WH. Welding fine thermocouples wires. Journal of Scientific Instruments. 1945;1:17-18.

[13] Hickson VM. The welding of thermocouples junctions. Journal of Scientific Instruments. 1940;17(7):182-186. http://dx.doi.org/10.1088/0950$7671 / 17 / 7 / 303$

[14] Ghosh A, Muju MK, Parija S, Kanjrathinkal A. Microwelding using eletrochemical discharge. International Journal of Machine Tools \& Manufacture. 1997;37(9):1303-1312. http://dx.doi.org/10.1016/S0890-6955(96)00064-8.

[15] Zanstra PE. Welding uniform sized thermocouple junctions for thin wires. Journal of Physics. E, Scientific Instruments. 1976;9(7):526-528. http://dx.doi.org/10.1088/0022-3735/9/7/004.

[16] Real Therm. 2016. [acesso em 21 nov. 2016]. Disponível em: http://www.realtherm.com.br/prod-tau-interna.php

[17] Amada Miyachi. Monrovia; 2016. [acesso em 21 nov. 2016]. Disponível em: http://br.amadamiyachi.com/products/resistance-welding/rwpower-supplies/thermocouple-welder

[18] VMV Costa. São Carlos; 2016. [acesso em 21 nov. 2016]. Disponível em: http://vmvcosta.com.br/\#blog

[19] Okumura T, Taniguchi C. Engenharia de soldagem e aplicações. Rio de Janeiro: LTC; 1982.

[20] Bejan A. Advanced engineering thermodynamics. 4th ed. New Jersey: John Wiley \& Sons; 2016. http://dx.doi.org/10.1002/9781119245964.

[21] American Society for Testing and Materials. ASTM E-230-98: standard specification and temperature-Electromotive-Force (EMF) tables for standardized thermocouples. West Conshohocken: ASTM; 1998. 